\title{
Social media institutionalization in the U.S. federal government
}

\author{
Ines Mergel \\ Department of Public Administration and International Affairs, Maxwell School of Citizenship and Public Affairs, Syracuse University, 215 Eggers Hall, Syracuse, NY 13244, United States
}

\begin{abstract}
A B S T R A C T
Social media adoption changes the existing organizational technology paradigm of public sector organizations. This paper explains the internal decisions that are necessary before new technologies can be used to support the strategic mission of a government organization and which behavioral and technological changes are integrat ed into the organization's standard operating procedures. This is an important theoretical contribution, because social media technologies are developed and hosted by third parties outside of government, with government's role limited to reactively evaluating their internal needs, strategic alignment, and existing routines. Evidence from qualitative interviews with social media directors in the U.S. federal government and a digital ethnography of their online practices expand the existing theory of social media adoption by adding two distinct activities: strategic alignment and routinization which lead to the institutionalization of new technologies.
\end{abstract}

Keywords:
New technology adoption
Institutionalization
Social media
U.S. federal government

\section{Introduction}

Social media use among the federal agencies in the U.S. executive and legislative branches has become an accepted technology use to interact with the public in general, with other government agencies, and also to collaborate internally. The adoption of social technologies that are owned by third parties oftentimes constitutes a challenge for public man agers. They have to rely on external technology platforms designed and hosted outside of government, which involves uncertainty of changes in the platforms, and uncontrollable cybersecurity risks that have to be mitigated by the platform providers. Agencies cannot opt out of revisions of the technology. They cannot hire contractors to outsource changes or request customization services to platforms to accommodate govern ment needs. Public managers in charge of social media accounts are therefore exposed to constant changes of the platforms and at the same time have to deal with emergent citizen and employee behavior that challenge government's one directional communication paradigm. The social behavior and culture evolving around social media technologies puts agencies in a reactive mode and formal mechanisms, such as social media policies and organizational structures subsequently have to be adapted as a result of the observed user behavior and technological changes (Mergel and Bretschneider 2013).

Most of the experience using social media was derived from President Obama's first presidential campaign in 2008 and replicated in his second run for office in 2012 (see for example: Shirky, 2011; Smith, 2009). Social media was heavily used by campaign staff to increase citizen participation and helped to influence online users of so cial media sites to change their behavior: people were moved from

E-mail address: iamergel@maxwell.syr.edu. online interactions with the candidate to offline actions such as register ing to vote and then showing up at the voting booths on Election Day. Social media played a crucial role in targeting citizens who have already registered, but were unsure who to vote for and also to use those with a clear choice to convince their friends in their online networks to vote for the candidates (Hong and Nadler 2012). Even though a political cam paign has some parallels to the goals of a communication strategy in the public sector, the most common mission relevant communication focuses on educating and informing the public. The goal is usually to passively inform the public, potentially improve transparency of opera tions, and if possible improve buy in for government actions. Calls for action, such as specific behavioral changes are left to certain agencies in volved in emergency situations, such as food or drug recalls or disaster preparedness and response.

Government agencies evaluate how social media can support their mission beyond the formal informing and educating goals and potential innovative practices that social media tools allow them to implement. These strategic decisions are highly context specific. Organizations like NASA that is fan based have very different organizational missions than regulatory agencies with an enforcement mandate. The decisions on how to institutionalize social media and integrate new routines in the existing communication strategy are therefore highly individual to each government organization and evolve over time as Mergel and Bretschneider (2013) in their phased model of social media implemen tation showed.

The research questions addressed in this article are: how do government agencies in the U.S. federal government agencies of the executive branch approach the formalization and institutional ization of social media by adapting their internal organizational and institutional norms and regulations and standard operating procedures? 


\section{Social media use in the public sector}

Defined as "services that allow users to create an online profile and that also enable user generated content, crowdsourcing, and online collaboration" (Mergel, 2012b:12), social media tools have the potential to connect citizens directly to government communicators and other citizens in real time. Government organizations are using social media tools as a public affairs communication medium to increase transparen cy by sharing content that citizens are otherwise not aware of or cannot easily access through a government organization's website or other offline media. The high acceptance rate of social media tools is reflected in the fact that all federal agencies today have a social media presence. In addition, $84 \%$ of local and state governments in the U.S. are represent ed on social media (Mergel, 2012a, 2013a).

Social media applications are used for a wide range of purposes depending on the mission of the organization. The majority of govern ment agencies are using social media tools to replicate already existing content from their websites or to point citizens to information that is already available online. The main purpose is to increase trust in gov ernment operations by providing more frequent and transparent online information. This new form of representation can be seen as the lowest degree of online engagement and is oftentimes misinterpreted as true citizen participation. More complex forms of interactions include active calls for engagement in form of submissions to photo contests, requests to submit information in form of blog comments or even citizen science and open innovation initiatives encouraging citizens to contribute knowledge or conduct micro tasks online.

There is very little evidence so far that government agencies are using social media applications as an e government service, delivering customer service beyond the response to citizen requests or for complex and event driven interactions, such as active one on one communica tion or direct responses during emergency management services (see for example Kavenaugh et al., 2011). The potential however to close the gap between potentially flawed perceptions of government actions and the formal information government tries to transmit is still im mense. Government agencies need to adapt their existing organization al routines to monitor, interpret and respond to social media interactions. It is therefore important to understand the current internal management practices and existing rules and regulations that lead to the routinization efforts of social media output and interactions.

\subsection{Social media as innovative government technology adoption}

Existing theories of innovation and technology adoption in the public sector focus on policy adoption and the resulting technology adoption. As an example, Rogers and Shoemaker provided a model that showed the growing numbers of adopters over time in aggregation over the whole population of potential adopters (1971). Innovation needs to be communicated through a network of adopters who can then observe each other's behavior. That also means that the visibility and observability of innovative practices is important, so that diffusion and replication can occur. In the case of social media practices this condition is fulfilled: each government account in the U.S. federal government is publicly accessible on the agency's website and most interactions are observable in an agency's social media timeline.

Other authors have shown that technology adoption occurs in stages (Coursey \& Norris, 2008; Nolan, 1973): adopters can be divided by their speed of adoption from early adopters to laggards or from those adopters who are moving from the acceptance of simple technologies to complex technologies. Mergel has shown in her research on social media adoption phases that federal government agencies in the U.S. were initially engaging in a fair amount of experimentation that has then led to formal practices (Mergel, 2010, 2013a,b). While diffusion might be high, the extent of use varies especially when it comes to more complex or diverse practices.
The existing rules and regulations in a bureaucratic setting mitigate the extent of acceptance of new technologies and might even delay adoption (Fountain, 2001; Kraemer \& King, 2003). This also explains that technology adoption is usually seen as an investment decision that is made top down and rolled out throughout the organization. Technology acceptance follows existing policies and guidelines and has to be aligned with the existing technology use paradigm in government organizations.

Previous research has shown that government follows different adop tion patterns especially when it comes to the different purposes or tasks that are conducted through social media, such as increases in participa tion and transparency (Bennett \& Elman, 2006; Oversightandreform, 2012; Tansey, 2007) or the potential to respond in emergency situations (see for example Kavenaugh et al., 2011). Other research has focused on observable online tactics (Davis, 1989; Mergel, 2013b; Simon, 1976) and the effectiveness of these tactics (Sobaci \& Karkin, 2013; Takhteyeva, Gruzdb, \& Wellman, 2012; Venkatesh \& Davis, 2000). Most of these stud ies focus either on publicly observable online practices that can be ex tracted from the Web and individual social media accounts. Or they focus on citizen behavior and how the public interacts through social media with government organizations (Linders, 2012). The data is then used to deduct adoption patterns and potential outcomes.

Mergel and Bretschneider have suggested a staged model explaining organizational dynamics of social media adoption moving from stage 1 with high degrees of experimentation, to stage 2 of "constructive chaos" to institutionalization in stage 3. Each stage is characterized by varying degrees of online interactions and maturity of practices. They hypothe size, that the degree of interaction declines with increasing formaliza tion and suggest that organizational behavior cannot necessarily only be interpreted based on the output observable on social media sites (2013). Instead, it is necessary to understand internal decision making processes in the context of existing organizational routines and con straints that govern these institutionalization decisions. This paper therefore focuses on the third stage that is rarely publicly observable: the decisions that lead to the institutionalization and routinization of social media adoption. Focusing on this third stage contributes to the expansion of Mergel and Bretschneider's theory. Rogers (2010) sug gests that implementation of an innovation occurs when the innovation is incorporated into regular activities of the organization and the inno vation is no longer alien to the organization. Otherwise it will lead to a discontinuance or failure of the innovation process. This article there fore sets out to answer the following research questions: How are social media practices institutionalized in government?

\subsection{Data collection and analysis}

Data for this article were collected using a digital ethnography ap proach over the course of five years from 2009 to 2014. The researcher participated in ongoing online interactions with the social government communicator community on the microblogging service Twitter using the search hashtags \#Gov20, \#SocialGov and \#GovTech a collection of keywords that are mainly used by government social media profes sionals. The digital ethnography approach is similar to methods, such as Kozinets' netnography, a form of ethnographic research adapted to include the Internet's influence on in this case government commu nication behavior (Kozinets, 2010). Problem statements and problem solutions provided by the community were extracted from online con versations and the researcher actively participated in online conversa tions by sharing insights, research and practitioner reports, Twitter updates, practitioner oriented Op Eds on government technology news websites and a research blog, as well as through teaching online classes for GSA's digital government university. Prior forms of online ethnographies, for example conducted by West, focused on similar non participant observations of online tactics (Norris \& Moon, 2005; West, 2005). West created an inventory of online services by extracting the number of interactive elements available on government websites 
and tracked changes over time. In this article, the focus of online ob servations was on social media interactions of government officials by tracking their behavior on all available social media channels, as well as their articulated problem statements and resolutions provided on line to the community. The content and number of interactions were tracked on social media accounts that are directly linked from a department's official websites, as well as those social media accounts that are only established on third party platforms and their content is distributed through those social media services that were directly linked from the homepage. Throughout the digital ethnography process, changes in online behavior of government entities were re corded and stored in notes that were subsequently used for the qual itative data analysis.

In addition, social media directors in the 15 departments of the exec utive branch in the U.S. federal government participated in interviews. The interviews were recorded with the permission of the interview partners and then transcribed verbatim. The goal of the data collection was to obtain a close to complete inventory of all cabinet offices and ad ditional interviews with sub agencies and independent agencies that were mentioned by the interview partners as innovators were added to the initial set of interview partners (Judd, Smith, \& Kidder, 1991). This snowball sampling approach started with innovators that were identified by the researcher and with each interview partner additional contacts were established and interviews were added to the final set of 22 interviews.

The sampling approach can be labeled as a non probability targeted sampling. The social media directors included in the data set were either organizationally embedded in the IT or website administration as part of the Chief Information Officers responsibilities $(10 \%)$ or in the Public Affairs offices (90\%).

The interviews lasted between 60 and $90 \mathrm{~min}$. The interview out line was semi structured and constructed based on the initial online observations (Glaser \& Strauss, 1967; Strauss \& Corbin, 1997). The interview guideline covered a wide range of topics, including the strategic intention of the use of social media, mission support, organi zational embeddedness, roles and responsibilities, internal decision making processes as well as implementation processes, day to day governance and management practices, resulting online tactics, per ceptions of best practices across the federal government and outside of government (in the business and nonprofit sectors), and measure ment of online impact.

The data analysis applied a triangulation approach (Jasperson et al., 2002): Observable online behavior indicating the extent of social media adoption in the public sector and the formally articulated organizational intent extracted from social media handbooks and policies were used to inform the initial interviews with social media directors. In turn their articulated perceptions of the organizational decision making processes were compared to the available documents and more importantly to the web coding results of observable online practices. Over time, a pro cess tracing approach was used to understand how top down policies from the White House, the Office of Management and Budget (OMB), the Office of Science Technology Policy (OSTP) and the Government Ac countability Office (GAO), as well as best practice guidance available through General Services Administration's (GSA) HowTo.gov website were integrated into organizational practices (Bennett \& Elman, 2006; Collier, 2011; Tansey, 2007).

Following Bertot et al.'s overview of policies and guidelines directing the use of social media in the U.S. government (Bertot, Jaeger, \& Hansen, 2011), an archival and document analysis provided the emergent insti tutional framework in which social media interactions evolved. Initially, social media use was interpreted as e government use already covered by the provisions stated in the 2002 e Government act (United States Congress, 2002), which directs agencies on how to use email and Inter net technologies. However over time it became clear that the use of third party platforms that are not hosted in government but by busi nesses in the cloud may need additional guidance. GAO subsequently released reports which in turn initiated institutional responses by OMB and OSTP as well as procedural guidance by GSA (see for example: GAO, 2011, 2012). Individual organizational units then created internal social media guidance, such as social media handbooks, guides, strate gies or policies which help to guide both employee and citizen behavior that were taken into consideration to understand organizational change and formalization of routines.

The process tracing data was subsequently triangulated with the web coding data and web narratives from the interviews in an iterative process. The theory driven "within case" analysis of the qualitative data were based on first hand reports of internal decision making processes that led to the final decisions about how to institutionalize social media use by each of the departments.

\subsection{Evidence for social media institutionalization in the public sector}

Social media institutionalization occurs along a continuum of practices that moves from convergence of routines and standards, the alignment of the innovative practices with the organizational mission to the integration of social media into the existing technology paradigm and the standard operating procedures in public affairs communication.

\subsubsection{Centralized vs. decentralized convergence of practices and routines}

Convergence of social media innovations occurs because more and more government organizations are using a wide variety of online prac tices, varying degrees of engagement, and often times duplicate social media accounts in the same organization. As a result, the Government Accountability Office issued a report which highlighted the risks of the wide ranging and uncoordinated social media use across departments (GAO, 2011). Institutional governance mechanisms such as this call for standards in form of formal social media strategies and policies then impact the creation of organizational formalization efforts.

So called "business cases" of potentially harmful online behavior and overlapping, uncoordinated activities increased the awareness of risk taking behavior of intrapreneurs experimenting with social media. At the same time, social media interactions and the positive im pacts of engaging in a more direct way than ever before showed the value social media can potentially have for government organizations.

As one social media director states:

"We draft policies, procedures, guidance for best practices as a group and then those are enforced throughout the various folks that are in volved in social media. It's driven by the communication needs as well as what people bring to the table, their needs, and then that sets the agenda for what guides things to be addressed at what time."

Other departments, start with a single social media strategy for one specific initiative, such as HealthCare.gov, and roll them out as other projects or initiatives emerge:

"A strategy in the sense that people have seat down and talked about it, and it's still sort of being worked out the details. But it's on paper: This is our goal, these are our target audiences, things along those lines. Social media strategies then pop up with all different projects. We do not have an [overall] explicit strategy, larger for the depart ment. There is no huge [department] social media, new media com munication strategy. Part of that is because things bounce all over the palace. The [department] is so huge. We set some guidance, and some parameters around which people can use, and build their own social media communication strategy."

This shows that public managers recognize the need for standardiza tion and streamlining of behavior, the organizational reality is oftentimes emergent with events, projects or initiatives that are started in dispersed parts of the organization. Larger departments such as Department of Defense (DOD) or Department of Health and Human Services (DHHS) 
have in itself not a unified organizational management structure. As one of the public managers stated:

"[Our agency] is rather centralized, so they have a more central ized strategy, in the sense that it is only one [agency] account. On the other hand we have [subagency], which has a decentralized organizational structure in and of itself, so they have elected to be incredibly decentralized in the social media commu nication strategy, and empower the different offices within [subagency] to come up with their own. Those are only two of the operational divisions across the 12 . There is a lot of variability across the department for sure. "These standard setting efforts al so result in new organizational rules for both government em ployees and their online behavior on behalf of the agency, but also in their private use and for citizens and other stakeholders interacting online with the agency. These procedural governance mechanisms in form of official social media strategies and policies formally document appropriate behavior and new standards, but also limit the autonomy of individual intrapreneurs who were experimenting with social media. As a result, social media direc tors are more aware of potential risks and limit their online tactics to mostly a push mode and relatively few interactive responses to inquiries via social media or interactive pull modes.

\subsubsection{Institutionalization: strategic alignment and routinizing of behavior and norms}

Institutionalization in form of widespread use of new technologies occurs when the meaning of the new innovation gradually becomes clearer to the organizational members. It usually occurs after periods of experimentation and consolidation have occurred the two initial stages described in Mergel and Bretschneider's model (2013). Correc tive actions occurr and unwanted side effects or unintended behavior are eliminated: As an example, the U.S. Army revises its social media handbook every year. The organization moves on into stable arrange ments and can rely on the adapted norms and procedures: social media becomes embedded in the organization structure and the organi zation agrees on a common understanding. When these clarifying steps have been taken, the organization needs to recognize the potential of social media for its own mission.

The strategic alignment phase of the institutionalization occurs as social media managers made sense of the usefulness of social media practices to support the mission of their government agency. The sub jects interviewed for this study provided four different mission support mechanisms that helped to integrate social media practices into the existing standard operating procedures of their public affairs offices. The following technology practices reflect the conceptual fit with an or ganizational problem to solve a public affairs problem:

Social media innovations were used as a tool to create awareness and support for programs, services, and to increase democratic under standing of participation and transparency. Especially agencies that are dependent on news coverage and interactions with the public to increase awareness for their programs have seen social media as an innovation that helped to distribute content, especially during times when traditional news outlets were diminished. As an example, the social media director of a prominent science and technology agency explained how social media technologies replaced news interactions:

"When we saw that the Houston Chronicle laid off their space re porter, it was a critical time for us. We saw that we were getting less and less coverage, especially when we landed two Rovers on Mars. [...] We saw the number of applications coming from media for our press room seats and it was the lowest ever. We used to get several hundred; we were getting about 50 that year. So, it be came really important for us to find a new way to get our news out. [...] In the meantime, we were seeing blogs and dedicated space on science blogs being operated by just amateur enthusiasts were starting to pick up steam and lot of them were even discussing about how would they get news about whether the landing had happened successfully or not. [...] We learned from the Twitter audience: the questions that were coming into us made go oh my gosh, I've taken for granted that the public under stood this aspect of a space mission, and now I'm seeing all the holes."

These external changes in the communication environment are counterproductive to the formalized goals of many government organi zations: most mission statements include a requirement to disseminate news to inform and educate the widest possible public. Social media al lows government therefore to fill an organizational need to support the core mission of each agency.

The quote above also shows how communication with the public changed from a third person reporting standpoint that is oftentimes la beled "press release style" and occurs after an incident, to direct inter actions with citizens. The second innovation that this quote highlights is that the content that is now communicated through social media changed from government centric pushing of content to citizens, to a citizen centric pulling of content and ideas that the public is actually in terested. As the social media director says:

"We've done something wrong, something was lost in translation. Then we started getting all these messages then that taught me that we need to set up things better, that we need to explain in advance exactly what people can expect. [...] We are much more careful in spelling out things that to us have always seemed extremely obvious, but we realize was not obvious to the public."

As a result, communication routines have changed:

"We take great pride that our Twitter account is not just pushing out information. More than $50 \%$ I think probably close to $70 \%$ of what we post is a response to somebody, not just an announcement of some thing. Anytime we make a post we know that we're going to be mon itoring the account for a few hours so that we can respond to questions or clarify information, and every one of our tweets has a call to action, whether it's looking at photograph, whether it's cling on a link to learn more, or click, going to a video to learn more."

In a similar context, some agencies are connecting to their citizen 'fanbase' on social media an interaction that was not available before social media innovations made direct interactions on a large scale pos sible. These are usually agencies that have unique content to share, such as landscape or space pictures that only the agency itself creates and no other content provider can create similar content in the same extent, ac cess, and quality. These interactions create a new form of trust and con tinued interest in the work and programs of the agency. This trust then helps to create future support for budget allocations and programs (for example to keep the space program alive or make sure that people use the public land). Beside innovative interaction opportunities to support these indirect outcomes of social media, the resulting routines are ex plained by one of the social media directors:

"It's based on the content that we have got. So if we have a really stunning image, we want to use that. What we try to do basically is have ten polls for the day. So around 11:00 every morning we put out a photo on Instagram and a photo on Twitter. Every eve ning around 6:00 we do the same. And then depending on the what we have got in between, that's where we try to fit every thing else in. For example, we had an announcement that more people visited national parks in 2014 than any other year. So we developed a strategy on Twitter for pushing out those tweets, let ting people know that national parks are becoming more popular than ever, but also letting people know that for every tax dollar invested in the national parks, it returns $\$ 10$ to the local economy. 
On all our social media accounts, we have developed a strategy of using really striking imagery to go along with that information so people are more likely to share it.

As the examples above show, both external and internal factors led to actions that redefine the use of the technology to accommodate the organization's needs and structure more closely. For example, NASA does not just use social media to distribute unique pictures provided by the Mars Rover, but also uses social media to reach out to audiences who might have unique knowledge to contribute to problem solving through their citizen sourcing projects. Here two problems are solved where one is not directly related to the initially intended use, but expands the use as new organizational needs occur. Similarly, another department was looking for unconventional mechanisms to create content. Their social media director explains their decision making process:

"We wanted to do something where we actually engaged people and got them to an event. So we did our first Instameet, which we called a Monumeet, which we did around the opening of the Washington Monument, which had not been open since the earth quake from 2010 or '11, I believe. So we wanted a new and interest ing way to cover an event, so we asked people if they wanted to come and actually be our photographers on scene. We received over 700 applications for 12 spots. Attendees covered all demographics, so it wasn't just young people. [...] We received tremendous press from this, not only just reaching out to these people's followers, but Mashable covered it and the CBS Evening News actually ran a $21 / 2$ minute bit that night on a teacher that we had invited who wanted to cover the event because his kids were in a low income ar ea and they didn't have the money to go to Disney world which was across the street in Florida, let alone to DC and see the monuments.

However, routinization only occurs when these specific organiza tional needs are met with social media technologies. One need that is met because content is now readily available that is easily spread through social media:

"What we have learned over the last $4 \frac{1}{2}$ years is that content is king. You can have the greatest strategy ever, but if you don't have the content to go with it, it's probably not going to go anywhere. Give people something they can't find anywhere else, which is why we are uniquely positioned to share rare photos of wildlife that have been taken. [...] Use photos and video where possible. These social media accounts are becoming more and more visual everyday. We've almost got to the point at [the department] where we don't post any tweets unless there are photos associat ed with them.

The result is that not every organize will institutionalize social media to the same degree, instead variation occurs depending on the strategic alignment, matching, and routinizing efforts and the ex tent to which restructuring and adaptation of the existing standard operating procedures is necessary. The changes in the routines frequent and standardize updates available on social media might also impact the environment of the organization (Van de Ven, 1986). Zavattaro and Sementelli for example explained the expecta tions of omnipresence availability of an agency $24 / 7$ on social media (2014).

As social media innovations reach the status where routines are standardized, no online interactions are left to occur randomly. Social media is part of the overall organizational communication strategy and embedded in the ICT standards of the organization. In some organi zations this includes pre approval of new social media accounts or the centralization of all social media activities. In addition, organizational resources are expanded to meet the adapted standard operating pro cures as one social media director explains:
"We have a director, a deputy director who mostly focused on [the department's website]. We have a social media strategist, or digital engagement strategist who is handling the day to day posting, coming up with content, working without bureaus on developing strategies. We have a videographer who does [a weekly feature]. We also have a staff photographer who usually travels with the Secretary and photographs events. And then we have a content specialist who id doing mostly international com munications, sharing employee stories. And then also we have contractor who is doing all the development work on [department website]."

Routinizing is then reached when social media is not longer seen as new, but part of the standard operating procedures and absorbed in the organizational structure. And he further explains, that social media re sponsibilities are part of the standard public affairs department:

"We are part of the larger communications team: we are fully integrated with traditional media. We have daily meetings where were are working on professionally spelling out what it the digital application. That teams is very good about knowing that we are not just getting to feed our press releases, that's not a very exciting digital strategy, but pulling content from that. And they are good at listening and going along with our ideas. It's a really integrated team."

These mechanisms as part of the routinization also impact organiza tional procedures and management practices. As an example, GSA has developed editing tools for social media use. Desktop tools, like Mea sured Voice, provide an editing template for social media updates with a clear hierarchical approval mechanism: one employee crafts the initial social media update, moves it through the approval process to a super visor or managers, who edits and potentially re edits before messages are moved off the desktop to the live social networking site. These rou tines remind of formal public relations information vetting procedures that have been established for years and are applied for press release editing needs. One social media director highlighted: "I said earlier that I stole language from media advisories. I'm stealing actual text from a document."

While formalization might sound counterproductive to the interac tive, fast and furious nature of social networking sites, these profession alization efforts show mission driven diversity of communication needs. Social media directors create diverse modes of online interac tions and are adapting them based on organizational needs and align them with the mission of the organization.

\section{Conclusions}

Social media innovations are occurring inside and outside of govern ment. Technology companies are changing the technology itself and cit izens are changing their behavior. Government agencies are therefore experiencing a need for constant realignment. Otherwise the routinized use might lead to what Rogers calls misalignment and the organizatons might abandon or reduce to minimally invasive practices, such as return to old routines of only publishing after action reports and press releases.

In conclusion, social media adoption is impacted by institutional and organizational mechanisms that direct the degree and extent of adop tion. The institutional mechanisms are oftentimes out of the control of the public managers interviewed for this study. Overarching institution al norms and regulations evolve as social media practices emerge and administrative needs evolve that result in formalization of behavior. Organizational governance mechanisms as a result then include chang es in management practices, such as the establishment of roles and re sponsibilities, or retroactive budget allocations for capacity building. Both, institutional and organizational governance mechanisms, influ ence the interactivity of online tactics. 
Similar to previous waves of e government and ICT adoption, social media adoption follows a diffusion curve (Rogers, 1976, 1995, 2005). In early stages of the adoption of a new technology, there seems to be enough bureaucratic discretion to experiment with a variety of social media tools and modes of online interactions, however as organizations are making positive and negative experiences with social media, more and more institutional and organizational governance processes and procedures are designed to be in alignment with the hierarchical norms and standard operating procedures of the accepted technology standards.

This study also shows that while many institutional and organi zational routines and norms are persistent across waves of technol ogy innovations, external triggers create motivation to adapt new technologies. Even if there might be a phase of innovative behavior that is pushing the boundaries of the acceptable use of technology, the responses of the bureaucracy itself result in new routines and adaption of the standard operating procedures (Simon, 1976). As the organization adapts the existing standard operating proce dures, increasingly existing norms are adjusted to the novel context, providing context for the use and autonomy for organizational embeddedness.

User acceptance both inside government and outside of govern ment by citizens is clearly high, what this study shows is that technol ogy acceptance has to be aligned with the organizational mission, fit into the existing organizational needs, standard operating procedures and acceptable IT standards that are currently in place or replace procedures that have become obsolete (Davis, 1989; Venkatesh \& Davis, 2000).

\subsection{Limitations and future research}

This article focuses on a very specific subset of digital government interactions through social media channels and a very distinct sample of government organizations the executive departments of the U.S. federal government. While their online practices are emulated in other branches of the federal government, as well as across the state and local government levels, they might not be representative for e government in general or for all modes of online interactions. It is necessary to conduct additional large scale surveys to understand what the impact of these online interactions is. Unanswered questions include for example: Do citizens perceive that government is more in teractive, responsive, transparent, participatory and collaborative as a result of their use of social media channels?

In addition, government interactions do not follow only one type of online communication mode. As a matter of fact, there is lots of convo lution in the literature and researchers collapse the use of social media in local government departments. As an example, mayors have different intentions in their online interactions than for example police depart ments. Political actors, such elected officials, like Members of Congress, are constantly on the campaign trail and are less likely to deliver online services through social media channels. Police and other types of first responders in turn, do not always communicate in the same mode. They need for online interactions changes based on their event driven need to communicate, trust building campaigns between events, and general community service. Online communication modes will vary and additional research is needed to understand the difference between modes and their actual impact on citizens (Mergel, 2013a). Future re search therefore needs to focus on deriving different social media com munication modes that will differ across organizational mandates, situational needs, and type of online actors.

\section{References}

Bennett, A., \& Elman, C. (2006). Qualitative research: Recent developments in case study methods. Annual Review of Political Science, 9, 455-476.
Bertot, J. C., Jaeger, P. T., \& Hansen, D. (2011). The impact of policies on government social media usage: Issues, challenges, and recommendations. Government Information Quarterly, http://dx.doi.org/10.1016/j.giq.2011.04.004.

Collier, D. (2011). Understanding process tracing. PS: Political Science and Politics, 44(4), 823-830.

Coursey, D., \& Norris, D. F. (2008). Models of e-government: Are they correct? An empirical assessment. Public Administration Review, 68(3), 523-536 (Retrieved from 10. 1111/j.1540-6210.2008.00888.x http://search.ebscohost.com/login.aspx?direct= true $\& \mathrm{db}=21 \mathrm{~h} \& \mathrm{AN}=31389860 \&$ site $=$ ehost-live $)$.

Davis, F. D. (1989). Perceived usefulness, perceived ease of use, and user acceptance of information technology. MIS Quarterly, 13(3), 319-340.

Fountain, J. E. (2001). Building the virtual state: Information technology and institutional change. Washington, D. C.: Brookings Institution Press.

Gao (2011). Challenges in federal agencies' use of web 2.0 technologies. Washington, DC Retrieved from http://www.gao.gov/new.items/d10872t.pdf

GAO (2012). Federal law should be updated to address changing technology landscape. Retrieved from Washington, D.C. http://www.gao.gov/assets/600/ 593146.pdf

Glaser, B. G., \& Strauss, A. L. (1967). The discovery of grounded theory: Strategies for qualitative research. New York: Aldine Publishing

Hong, S., \& Nadler, D. (2012). Which candidates do the public discuss online in an election campaign?: The use of social media by 2012 presidential candidates and its impact on candidate salience. Government Information Quarterly, 29(4), 455-461.

Jasperson, J., Carte, T. A., Saunders, C. S., Butler, B. S., Croes, H. J. P., \& Zheng, W. J. (2002) Review: Power and information technology research: A metatriangulation review. MIS Quarterly, 26(4), 397-459 (Retrieved from < Go to ISI>://000179972700006).

Judd, C. M., Smith, E. R., \& Kidder, L. H. (1991). Research methods in social relations. Fort Worth (TX): Holt, Rinehart, and Winston.

Kavenaugh, A., Fox, E. A., Sheetz, S., Yang, S., Li, L. T., Whalen, T., ... Xie, L. (2011, June $12-$ $15,2011)$. Social media use in government: From the routine to the critical. Paper presented at the the Proceedings of the 12th Annual Inernational Conference on Digital Government Research, dg.O'11, College Park, MD, USA.

Kozinets, R. V. (2010). Netnography: Doing ethnographic research online. Thousand Oaks: Sage Publications.

Kraemer, K., \& King, J. L. (2003). information technology and administrative reform: will the time after e-government be different? Paper presented at the Heinrich Reinemann Schrift Fest, Post Graduate School of Administration, Speyer, Germany http://www.crito. uci.edu/publications/pdf/egovernment.pdf).

Linders, D. (2012). From e-government to we-government: Defining a typology for citizen coproduction in the age of social media. Government Information Quarterly, 29(4), 446-454.

Mergel, I. (2010). Government 2.0 Revisited: Social Media Strategies in the Public Sector. PA Times, American Society for Public Administration, Vol. 33 No. 3, p. 7 \& 10

Mergel, I. (2012a). A manager's guide to designing social media strategies in the public sector. Retrieved from Washington, D.C. http://www.businessofgovernment.org/ sites/default/files/Social Media Strategy Brief_0.pdf

Mergel, I. (2012b). Social media in the public sector: Participation, collabroation, and transparency in the networked world. San Francisco, CA: Jossey-Bass/Wiley.

Mergel, I. (2013a). A framework for interpreting social media interactions in the public sector. Government Information Quarterly, 30(4), 327-334.

Mergel, I. (2013b). Social media adoption and resulting tactics in the U.S. federal government. Government Information Quarterly, 30(2), 123-130. http://dx.doi.org/10.1016/j. giq.2013.05.015.

Mergel, I., \& Bretschneider, S. (2013). Theoretical model of adoption process with application to social media practices in the public sector: Where the formal and informal organizations meet! Public Administration Review, 73(3), 390-400.

Nolan, R. L. (1973). Managing the computer resource: A stage hypothesis. Communications fo the ACM, 16(7), 399-405.

Norris, D., \& Moon, M. J. (2005). Advancing E-government at the grassroots: Tortoise or hare? The Public Administration Review, 65(1), 64-75.

Oversightandreform (2012). Uncovered: Federal government worker "American idle"? Long Version and GSA Awards CeremonyYouTube.com

Rogers, E. M. (1976). New product adoption and diffusion. The Journal of Consumer Research, 2(4), 290-301 (Retrieved from http://links.jstor.org/sici?sici=0093-5301\% 28197603\%292\%3A4\%3C290\%3ANPAAD\%3E2.0.CO\%3B2-E).

Rogers, E. M. (1995). Diffusion of innovations (4 ed.). New York: Free Press.

Rogers, E. M. (2005). Adoption of innovation. New York: The Free Press.

Rogers, E. M. (2010). Diffusion of Innovation. New York, NY: Free Press.

Rogers, E. M., \& Shoemaker, F. F. (1971). Communication of innovations: A cross-cultural approach. New York: Free Press.

Shirky, C. (2011). The political power of social media: Technology, the public sphere, and political change. Foreign Affairs, January/February 2011. Retrieved from http://www.foreignaffairs.com/articles/67038/clay-shirky/the-political-powerof-social-media

Simon, H. (1976). Administrative behavior. New York: The Free Press.

Smith, A. (2009). The internet's role in the campaign 2008. Retrieved from Washington, D.C http://pewinternet.org/Reports/2009/6-The-Internets-Role-in-Campaign-2008. aspx

Sobaci, M. Z. \& Karkin, N. (2013). The use of twitter by mayors in Turkey: Tweets for better public services? Government Information Quarterly, 30(4), 417-425.

Strauss, A. L., \& Corbin, J. M. (1997). Grounded theory in practice. Thousand Oaks: Sage Publications, Inc.

Takhteyeva, Y., Gruzdb, A., \& Wellman, B. (2012). Geography of twitter networks. Social Networks, 34(1), 73-81. 
Tansey, O. (2007). Process tracing and elite interviewing: A case for Non-probability sampling. PS: Political Science and Politics, 40(4), 765-772.

United States Congress (2002). E-Government Act of 2002. DC: Washington.

Van de Ven, A. H. (1986). Central problems in the management of innovation. Management Science, 32(5), 590-607.

Venkatesh, V., \& Davis, F. D. (2000). A theoretical extension of the technology adoption model: Four longitudinal field studies. Management Science, 46(2), 186-204.
West, D. M. (2005). Digital government: Technology and public sector performance. Princeton: Princeton University Press.

Ines Mergel is an associate professor of public administration and international affairs at the Maxwell School of Citizenship and Public Affairs and the Information Studies School (ischool) at Syracuse University. Contact: iamergel@maxwell.syr.edu 